\title{
Impact of Granulation and Effect of Polymers on Theophylline Release from Matrix Tablets
}

\author{
Kazi Rashidul Azam, Md. Shaikhul Millat Ibn Razzak, Ferdous Khan, \\ Muhammad Shahidul Islam, Md. Ruknuzzaman Rony and Md. Selim Reza \\ Department of Pharmaceutical Technology, Faculty of Pharmacy, University of Dhaka, \\ Dhaka-1000, Bangladesh
}

\begin{abstract}
The effects of plastic, hydrophilic and hydrophobic types of polymers and impact of granulation process were investigated on the release profile of theophylline from matrix systems. A comparative release characteristics were evaluated by the use of polymers from different theophylline matrices. Matrix tablets of theophylline using Methocel K4M, Ethocel $20 \mathrm{cps}$, Kollidon SR were prepared separately by direct compression and moist granulation process. In this investigation the feasibility of moist granulation technique in the development of sustained release matrix tablet of theophylline was studied. The kinetics of the dissolution process was determined by analyzing the dissolution data using various kinetic equations, e.g. zero-order, Higuchi and Korsmeyer equations. The mean dissolution time (MDT) was calculated for all the formulations. The analysis of the dissolution data showed that the release process involves erosion and diffusion. Drug release was different from different classes of polymeric matrices and from tablets prepared by different manufacturing processes. The results showed that the profile and kinetics of drug release were the functions of polymer type, polymer content and granulation process.
\end{abstract}

Key words: Theophylline, Moist granulation, Direct compression, Methocel K4M, Ethocel $20 \mathrm{cps}$, Kollidon SR

\section{INTRODUCTION}

In the last two decades, sustained-release dosage forms have made significant progress in terms of clinical efficacy and patient compliance. ${ }^{1}$ The matrix system is commonly used for manufacturing sustained release dosage forms because it makes such manufacturing easy. ${ }^{2}$ A wide array of polymers has been employed as drug retarding agents each of which presents a different approach to the matrix concept. Polymers forming insoluble or skeleton matrices constitute the first category of retarding materials, also classed as plastic matrix systems. The second class represents hydrophobic and water-

Correspondence to: Md. Selim Reza

Tel: +880-2-8612069; Fax: +880-2-8615583

E-mail: selimreza_04@yahoo.com

Dhaka Univ. J. Pharm. Sci. 7(2): 133-139, 2008 (December) insoluble materials that are potentially erodable; while the third group includes polymers those form hydrophilic matrices. Plastic matrix systems, due to their chemical inertness and drug embedding ability, have been widely used for sustaining the release of drug. Liquid penetration into the matrix is the ratelimiting step in such systems unless channeling agents are used. The hydrophobic and waxy materials, on the other hand, are potentially erodable and control the release of drug through pore diffusion and erosion. Polymers belonging to hydrophilic matrix systems, when exposed to an aqueous medium, does not disintegrate, but immediately after hydration develops a highly viscous gelatinous surface barrier which controls the drug release from and the liquid penetration into the center of the matrix system. ${ }^{3}$ 


\section{MATERIALS AND METHODS}

Materials used in this experiment are theophylline, which was a generous gift from Square Pharmaceuticals Ltd., Ludipress (BASF, Germany), Methocel K4M (Colorcon, USA), Ethocel $20 \mathrm{cps}$ (Dow chemical Co, USA), Kollidon SR (BASF, Germany), Avicel PH 101 (FMC Biopolymer, USA), Aerosil 200 (Degussa, Germany), and Magnesium stearate (Wilfrid Smith Ltd, UK). All the other chemicals used were of analytical grade.

Preparation of matrix tablets by direct compression technique. The method includes dry blending of the active ingredients with polymers, filler, lubricant and flow promoter followed by direct compression. The formulations of tablets for direct compression method are listed in Table 1. In all cases the amount of active ingredient was $300 \mathrm{mg}$ and the total weight of the tablet was $506 \mathrm{mg}$. Properly weighed rate controlling polymer (e.g. Methocel K4M, Kollidon SR, Ethocel $20 \mathrm{cps}$ ), Povidone k-30, ludipress, magnesium stearate, aerosil 200 and the active ingredient were taken in a blender and blended for about 10 minutes. Particular attention had been given to ensure thorough mixing and phase homogenization.

Table 1. Different formulations of theophylline matrix tablets prepared by direct compression technique

\begin{tabular}{|c|c|c|c|c|c|c|}
\hline \multirow{2}{*}{ Ingredients (mg) } & \multicolumn{6}{|c|}{ Formulation code } \\
\hline & FDC-1 & FDC-2 & FDC-3 & FDC-4 & FDC-5 & FDC-6 \\
\hline Theophylline (60\%) & 300 & 300 & 300 & 300 & 300 & 300 \\
\hline Povidone k-30 (5\%) & 25 & 25 & 25 & 25 & 25 & 25 \\
\hline Ludipress & 125 & 75 & 125 & 75 & 125 & 75 \\
\hline Methocel K4M (10\%) & 50 & - & - & - & - & - \\
\hline Methocel K4M (20\%) & - & 100 & - & - & - & - \\
\hline Ethocel $20 \mathrm{cps}(10 \%)$ & - & - & 50 & - & - & \\
\hline Ethocel $20 \mathrm{cps}(20 \%)$ & - & - & - & 100 & - & - \\
\hline Kollidon SR (10\%) & - & - & - & - & 50 & - \\
\hline Kollidon SR (20\%) & - & - & - & - & - & 100 \\
\hline Aerosil 200 & 4 & 4 & 4 & 4 & 4 & 4 \\
\hline Magnesium stearate & 2 & 2 & 2 & 2 & 2 & 2 \\
\hline Total weight/Tablet & 506 & 506 & 506 & 506 & 506 & 506 \\
\hline
\end{tabular}

Preparation of matrix tablets by moist granulation technique. In moist granulation technique small amount of granulating fluid (water) was added to a powder blend (containing active ingredients, Polymers). Then moisture absorbing material microcrystalline cellulose (Avicel PH 101) was added to absorb any excess moisture. By adding microcrystalline cellulose in this way, a drying step was escaped. ${ }^{4}$ Then magnesium stearate, aerosil 200 along with granules were taken in a blender and blended for about 10 minutes. Finally granules were compressed using a single punch tablet compression machine. The compression force and compression time were 2 tons and 5 seconds respectively. The formulations for moist granulation technique with their codes are listed in Table 2.
All the preparations were stored in airtight containers at room temperature for further study.

In vitro dissolution study. For sustained release theophylline tablets $\mathrm{pH} 4.5$ (monobasic phosphate buffer) was used as dissolution media according to USP test-2. ${ }^{5}$ The dissolution test was performed using $900 \mathrm{ml}$ of $\mathrm{pH} 4.5$ phosphate buffer at $37 \pm$ $0.5^{\circ} \mathrm{C}$. The apparatus USP XXII type 2 (paddle) was used at $75 \mathrm{rpm}$ speed. After 1, 2, 4, 6, 8 hours interval samples of $5 \mathrm{ml}$ were withdrawn from the dissolution medium and it was replaced with fresh buffer media to maintain the volume constant. The samples were filtered and diluted to a suitable concentration with buffer solution. The absorbances of the solutions were measured at $271 \mathrm{~nm}$ for theophylline by using a 
Shimadzu UV-1501 UV/Visible double beam spectrophotometer (Shimadzu, Japan). Percentage of drug release was calculated using an equation obtained from the standard curve.

Kinetic modeling of drug release. After completing in vitro dissolution of all the batches for eight hours, the data were treated with zero order equation $^{6}$ and Higuchi equations ${ }^{7}$ (equation 1-2 respectively).

$$
\begin{aligned}
& M_{t}=M_{0}+k_{0} t \ldots \ldots \ldots \ldots \ldots \ldots \ldots \ldots(1) \\
& M t=M_{0}-k_{H} t^{1 / 2} \ldots \ldots \ldots \ldots \ldots \ldots \ldots . .(2)
\end{aligned}
$$

In these equations, $M_{t}$ is the cumulative amount of drug released at any specified time ( $\mathrm{t}$ ) and $\mathrm{M}_{0}$ is the dose of the drug incorporated in the delivery system. $\mathrm{k}_{0}$ and $\mathrm{k}_{\mathrm{H}}$ are rate constants for zero order and Higuchi model respectively. These models failed to explain drug release mechanism due to swelling (upon hydration) along with gradual erosion of the matrix. Therefore the dissolution data were also fitted to well-known Korsmeyer kinetic equation ${ }^{8}$ to ascertain the mechanism of drug release.

$$
\log \left(M_{t} / M_{\infty}\right)=\log k+n \log t
$$

Where $\mathrm{M}_{\infty}$ is the amount of drug release after infinite time; $\mathrm{k}$ is the release rate constant which considers structural and geometric characteristics of the tablet; and $\mathrm{n}$ is the diffusional exponent or release exponent; indicative of the mechanism of drug release. For a tablet having cylindrical shape, when $n$ is below 0.45, the Fickian diffusion phenomenon dominates, and $\mathrm{n}$ between 0.45 and 0.89 is an anomalous transport (non-Fickian diffusion), often termed as first-order release. After the $\mathrm{n}$ value reaches 0.89 and above, the release can be characterized by case II and super case II transport, which means the drug release rate does not change over time and the release is characterized by zero order. In this case, the drug release is dominated by the erosion and swelling of the polymer. ${ }^{9-10}$ Mean dissolution time (MDT) was calculated from dissolution data according to Mockel and Lippold using the following equation. ${ }^{6}$

$$
M D T=\left(\frac{n}{n+1}\right) k^{-\frac{1}{n}}
$$

\section{RESULTS AND DISCUSSION}

To investigate the effects of polymer, their content level and granulation process on drug release twelve formulations were prepared (Table 1 and 2). Formulation FDC-1, FDC-2 and FDC-3 best fits with Korsmeyer kinetic model $\left(\mathrm{R}^{2}=0.996, \mathrm{R}^{2}=0.995\right.$ and $\mathrm{R}^{2}=0.999$ respectively) (Table 3 ). The values of release exponent (n) for the above mentioned formulations are $0.677,0.620$ and 0.551 respectively which indicates anomalous transport mechanism (coupling of the diffusion and erosion mechanism). ${ }^{8}$ Formulation FDC-4, FDC-5 and FDC-6 also followed Korsmeyer model $\left(\mathrm{R}^{2}=0.993, \mathrm{R}^{2}=0.996\right.$ and $\mathrm{R}^{2}=0.997$ respectively) (Table 3 ). The values of release exponent (n) for the Formulation FDC-4, FDC-5 and FDC-6 are $0.551,0.770$ and 0.840 respectively. In the same manner Formulation FMG1, FMG-2, FMG-3 best fits with Korsmeyer kinetic model $\left(\mathrm{R}^{2}=0.997, \mathrm{R}^{2}=0.997\right.$ and $\mathrm{R}^{2}=0.991$ respectively) (Table 3). The values of release exponent (n) for the Formulation FMG-1, FMG-2 and FMG-3 are 0.7, 0.76 and 0.82 respectively which indicate that the drug was released by anomalous transport. Formulation FMG-4, FMG-5 and FMG-6 followed Korsmeyer model $\left(\mathrm{R}^{2}=0.995, \mathrm{R}^{2}=0.995\right.$ and $R^{2}=0.994$ respectively) (Table 3 ). The values of release exponent (n) for the Formulation FMG-4, FMG-5 and FMG-6 are 0.69, 0.81 and 0.83 respectively.

MDT value is used to characterize the drug release rate from the dosage form and the retarding efficacy of the polymer. A higher value of MDT indicates a higher drug retarding ability of the polymer and vice versa. The MDT value was also found to be a function of polymer content, polymer nature and manufacturing process. MDT values for FDC-1, FDC-2, FDC-3, FDC-4, FDC-5 and FDC-6 were $4.36,5.68,3.8,7.59,3.25$ and 7.7 hours respectively (Table 3 ). MDT values were larger for those formulations which contained highest percentage of polymer. MDT values for FMG-1, FMG-2, FMG-3, FMG-4, FMG-5 and FMG-6 were $6.90,8.97,5.12,13.8, \quad 3.56$ and 5.37 hours respectively (Table 3). MDT values for formulations 
of moist granulation process were larger than those of direct compression.

Effect of granulation technique on drug release. In this investigation theophylline matrix tablets were prepared by different manufacturing technique such as direct compression and moist granulation. It was found that tablets prepared by moist granulation exhibit significant retard release of drug compare to those of direct compression and this technique can effectively be used for sustained release tablet preparation. In case of matrix tablet prepared with hydrophilic polymer such as Methocel
K4M (Formula FDC-1 and FMG-1) drug release was less in moist granulation compare to direct compression (Figure 1a). Methocel K4M is a cellulose derivative and forms a water-soluble gel after contact with water. This polymer forms a very viscous gel as it has a viscosity of $4000 \mathrm{cps} .{ }^{11}$ Drug diffusion through this viscous gel was difficult and Methocel K4M effectively retarded drug release. Water activate Methocel $\mathrm{K} 4 \mathrm{M}$ and result better agglomeration in moist granulation technique. Thus drug release from moist granulation was lower comparing to direct compression. In case of matrix

Table 2. Different formulations of theophylline matrix tablets prepared by moist granulation technique

\begin{tabular}{|c|c|c|c|c|c|c|}
\hline \multirow{2}{*}{ Ingredients (mg) } & \multicolumn{6}{|c|}{ Formulation code } \\
\hline & FMG-1 & FMG-2 & FMG-3 & FMG-4 & FMG-5 & FMG-6 \\
\hline Theophylline (60\%) & 300 & 300 & 300 & 300 & 300 & 300 \\
\hline Povidone k-30 (5\%) & 25 & 25 & 25 & 25 & 25 & 25 \\
\hline Avicel PH 101 & 125 & 75 & 125 & 75 & 125 & 75 \\
\hline Methocel K4M (10\%) & 50 & - & - & - & - & - \\
\hline Methocel K4M (20\%) & - & 100 & - & - & - & - \\
\hline Ethocel $20 \mathrm{cps}(10 \%)$ & - & - & 50 & - & - & - \\
\hline Ethocel 20 cps (20\%) & - & - & - & 100 & - & - \\
\hline Kollidon SR (10\%) & - & - & - & - & 50 & - \\
\hline Kollidon SR (20\%) & - & - & - & - & - & 100 \\
\hline Aerosil 200 & 4 & 4 & 4 & 4 & 4 & 4 \\
\hline Magnesium stearate & 2 & 2 & 2 & 2 & 2 & 2 \\
\hline Total weight/Tablet & 506 & 506 & 506 & 506 & 506 & 506 \\
\hline
\end{tabular}

Table 3. Kinetic parameters of theophylline release from different polymeric matrix tablets

\begin{tabular}{|c|c|c|c|c|c|c|c|c|}
\hline \multirow{2}{*}{$\begin{array}{l}\text { Formulation } \\
\text { code }\end{array}$} & \multirow{2}{*}{$\begin{array}{c}\% \text { drug release } \\
\text { after } 8 \mathrm{hrs}\end{array}$} & \multicolumn{2}{|c|}{ Zero Order } & \multicolumn{2}{|c|}{ Higuchi } & \multicolumn{2}{|c|}{ Korsmeyer } & \multirow{2}{*}{$\begin{array}{l}\text { MDT } \\
\text { (hrs) }\end{array}$} \\
\hline & & $\mathrm{K}_{\mathrm{o}}$ & $\mathrm{R}^{2}$ & $\mathrm{~K}_{\mathrm{H}}$ & $\mathrm{R}^{2}$ & $\mathrm{n}$ & $\mathrm{R}^{2}$ & \\
\hline FDC-1 & 77.78 & 9.22 & 0.981 & 27.46 & 0.973 & 0.677 & 0.996 & 4.36 \\
\hline FDC-2 & 64.03 & 7.46 & 0.968 & 22.50 & 0.984 & 0.620 & 0.995 & 5.68 \\
\hline FDC-3 & 83.78 & 9.93 & 0.973 & 29.82 & 0.981 & 0.551 & 0.999 & 3.8 \\
\hline FDC-4 & 50.15 & 6.23 & 0.979 & 18.51 & 0.964 & 0.84 & 0.993 & 7.59 \\
\hline FDC-5 & 93.89 & 11.67 & 0.978 & 34.72 & 0.967 & 0.77 & 0.996 & 3.25 \\
\hline FDC-6 & 72.58 & 9.11 & 0.988 & 26.75 & 0.951 & 0.86 & 0.997 & 7.7 \\
\hline FMG-1 & 57.4 & 6.81 & 0.985 & 20.21 & 0.967 & 0.70 & 0.997 & 6.90 \\
\hline FMG-2 & 42.13 & 5.19 & 0.978 & 15.48 & 0.970 & 0.76 & 0.997 & 8.97 \\
\hline FMG-3 & 62.8 & 8.01 & 0.970 & 23.83 & 0.959 & 0.82 & 0.991 & 5.12 \\
\hline FMG-4 & 35.63 & 4.28 & 0.981 & 12.76 & 0.972 & 0.69 & 0.995 & 13.8 \\
\hline FMG-5 & 89.26 & 11.18 & 0.980 & 33.10 & 0.960 & 0.81 & 0.995 & 3.56 \\
\hline FMG-6 & 65.54 & 8.21 & 0.983 & 24.20 & 0.954 & 0.83 & 0.994 & 5.37 \\
\hline
\end{tabular}

tablet prepared with hydrophobic polymer such as Ethocel 20 cps (Formula FDC-3 and FMG-3) drug release was also less in moist granulation in comparison to direct compression (Figure 1b). But when Kollidon SR (Plastic polymer) was used as rate-retardant (Formula FDC-5 and FMG-5), it was found that granulation process has little impact on drug release (Figure 1c). As Kollidon SR is Plastic polymer granulating water has no effect on its activity. Addition of water couldn't activate Kollidon 
SR and drug release was similar from tablets prepared by direct compression and moist granulation process.
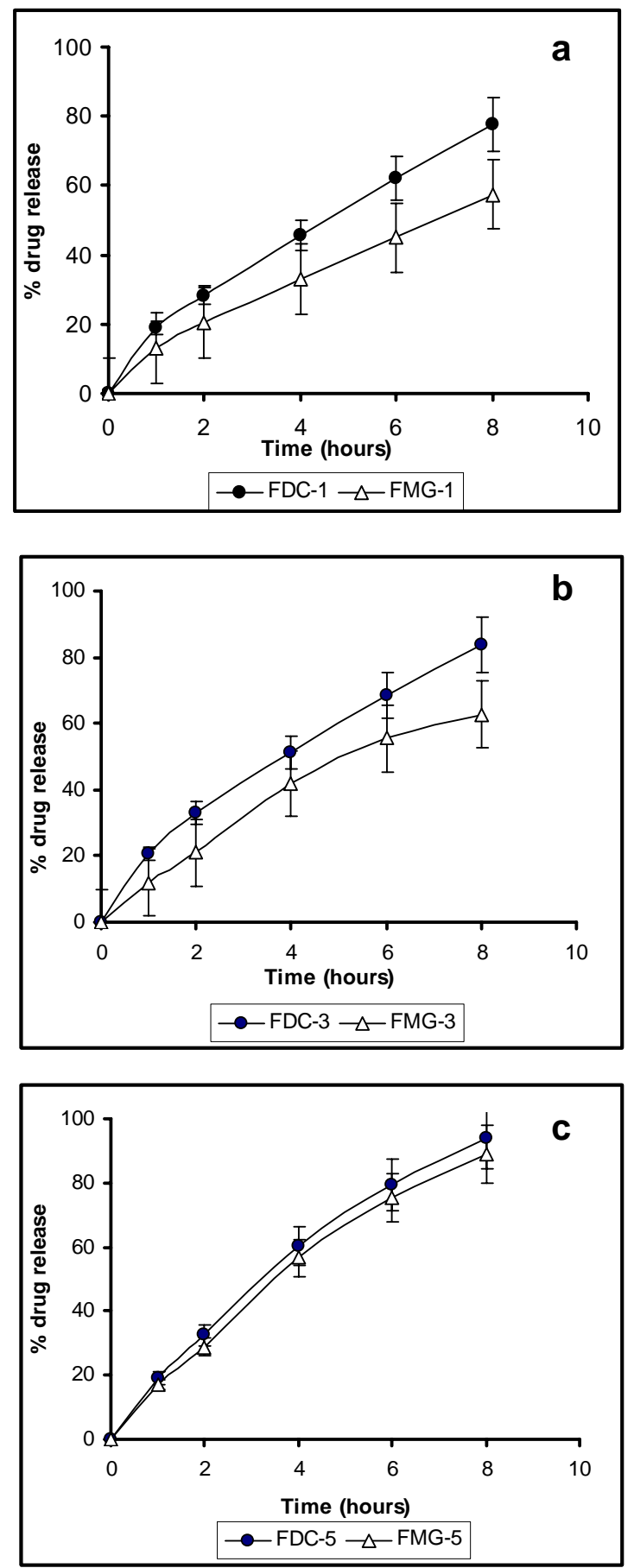

(c)

Figure 1. Zero order release profile showing effect of granulation on theophylline release from (a) Methocel K4M (b) Ethocel 20 cps (c) Kollidon SR based matrix tablets
Effect of polymer type on the drug release. The class and nature of the matrix forming polymers influenced the release profile of active ingredient. To explore the effect of polymer variation, formulation FDC-1, FDC-3 and FDC-5 were compared. The above formulations contained Methocel K4M, Ethocel 20 cps, Kollidon SR respectively and polymer content was $10 \%$ of total tablet weight in all cases. After carrying out dissolution for eight hours, it was found that drug release was highest with Kollidon SR compared to other two polymers (Figure 2). This might be attributed to dissolution of Polyvinylpyrrolidone (PVP) molecules, which are components of Kollidon SR that created pores and channels and thus facilitated solvent front penetration and elevation of drug release. ${ }^{12}$ Drug release from Methocel K4M was lowest because it formed a viscous gel layer through which drug diffusion was difficult. After solvation of the polymer chains, the dimensions of the polymer molecule increased due to the polymer relaxation by the stress of the penetrated solvent. This phenomenon is defined as swelling and it is characterized by the formation of a gel-like network surrounding the tablet. This swelling and hydration property of Methocel K4M caused an immediate formation of a surface barrier around the matrix tablet that impeded the burst release.

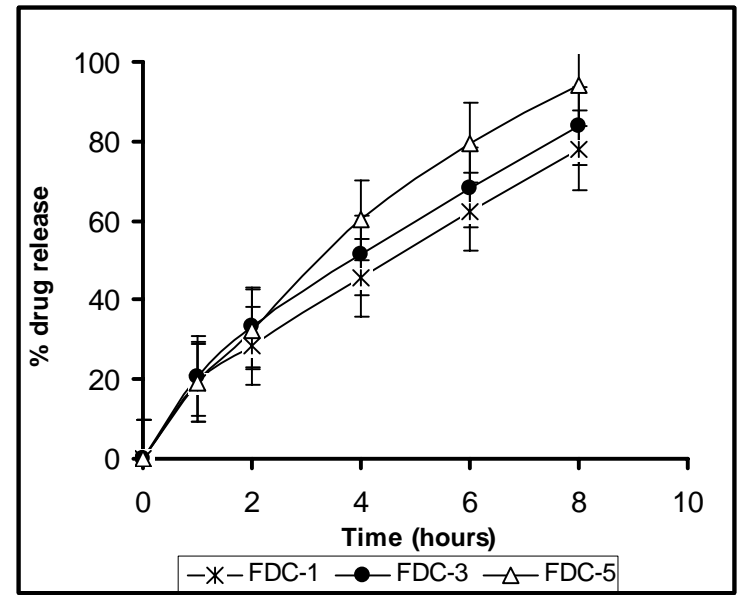

Figure 2. Zero order release profile of theophylline showing effect of polymers on drug release from matrix tablets

Effect of Polymer content on drug release. For all the formulations, it was found that drug release was inversely proportional to the content of rate 
retarding polymer present in the matrix system, i.e. the rate and extent of drug release increased with decrease in polymer content. It was observed that, formulation FDC-1 which contained 10\% Methocel $\mathrm{K} 4 \mathrm{M}$ offered $77.78 \%$ drug release at the end of eight hours whereas formulation FDC-2 which contained $20 \%$ Methocel K4M offered $64.03 \%$ drug release (Figure 3a). Such increase in the polymer content resulted decrease in the drug release rate due to decrease in the total porosity of the matrices (initial porosity plus porosity due to the dissolution of the drug). Similar phenomena were found for Ethocel 20 cps and Kollidon SR. In case of Ethocel $20 \mathrm{cps}$ matrix system $79.78 \%$ and $50 \%$ of theophylline were released from formulation FDC-3 and FDC-4 which contained $10 \%$ and $20 \%$ of polymer respectively (Figure 3b). Again for Kollidon SR matrix system $93.89 \%$ and $72.58 \%$ of theophylline were released from formulation FDC-5 and FDC-6 which contained $10 \%$ and $20 \%$ of polymer respectively (Figure $3 \mathrm{c}$ ).
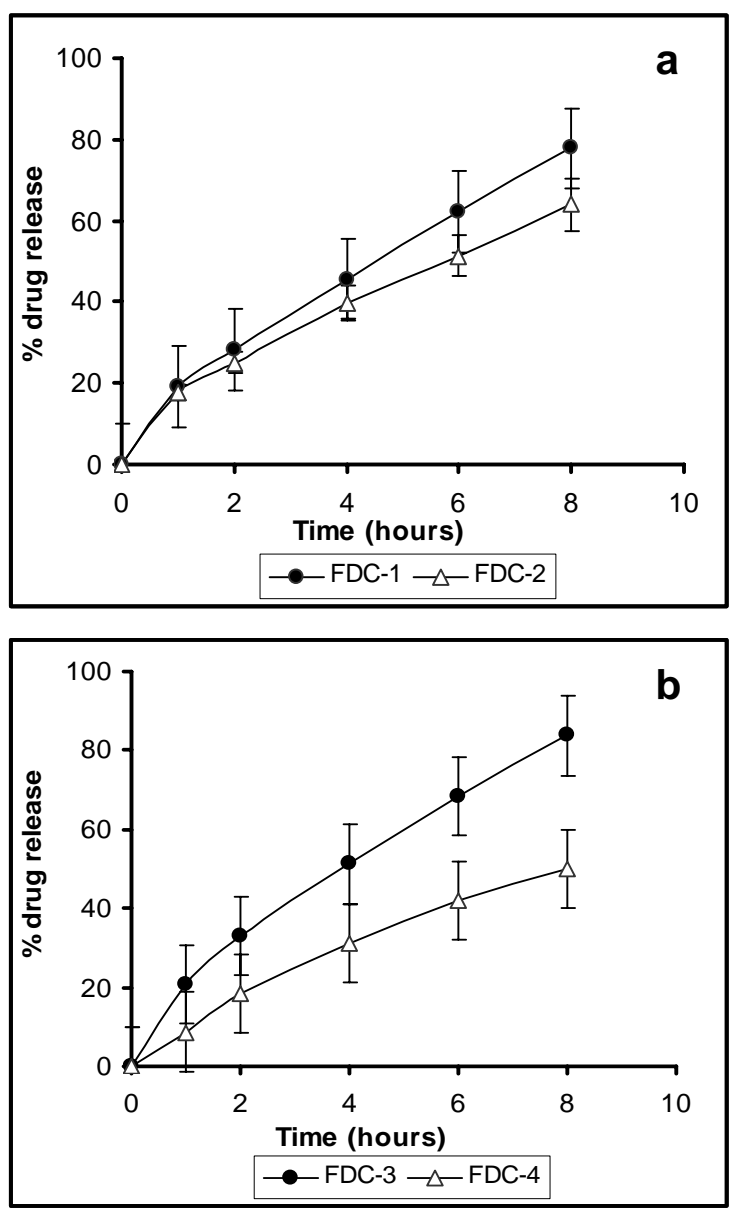

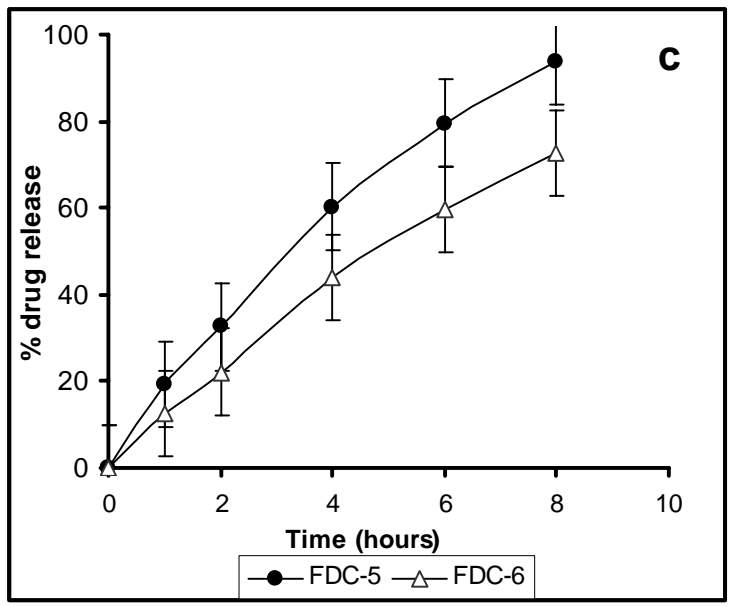

Figure 3. Zero order release profile of theophylline showing effect of polymer content on drug release from (a) Methocel K4M (b) Ethocel $20 \mathrm{cps}$ (c) Kollidon SR based matrix tablet

\section{CONCLUSION}

From the investigation it was found that tablets prepared by direct compression offered maximum drug release in all types of polymers than those were prepared by moist granulation technique. In case of matrix tablets prepared with plastic polymers moist granulation technique had insignificant impact on drug release. Among the three different types of polymers Kollidon SR showed more drug release than Ethocel $20 \mathrm{cps}$ and Methocel K4M. It was also observed that the rate and amount of drug release from all types of polymers were increased with decrease in polymer content. Thus a controlled plasma level profile of drug can be obtained by judicious selection of polymer, Polymer content and granulation process in the matrix system.

\section{REFERENCES}

1. Merkus, F.W.H.M. 1986. Controlled and rate-controlled drug delivery; principal characteristics, possibilities and limitations, in Struyker-Boudier, H.A.J. (ed.). Rate Controlled Drug Administration and Action, CRC Press, Boca Raton, FL, USA, pp. 15-47.

2. Cardinal, J.R., Matrix systems, in Langer R. S. and Wise D.L. (eds.). 1984. Medical Applications of Controlled Release, Volume 1, Classes of Systems, CRC Press, Boca Raton, FL, USA, pp. 41-67. 
3. Lachman, L., Lieberman, H.A. and Kanig, J. L. (eds.). 1990. Sustained Release Dosage Forms. In: The Theory and Practice of Industrial Pharmacy, 3rd edition, Varghese Publishing House, Bombay, pp. 453-454.

4. Railkar, A.M. and Schwartz, J.B. 2000. Evaluation and comparison of a moist granulation technique to conventional methods. Drug Dev. Ind. Pharm. 26, 885-9.

5. The United states Pharmacopoeia. 2004. $27^{\text {th }}$ edition, p. 1812.

6. Mockel, J.E. and Lippold, B.C. 1993. Zero order release from hydrocolloid matrices. Pharm. Res. 10, 1066-1070.

7. Higuchi, T. 1961. Rate of release of medicaments from ointment bases containing drugs in suspension. J. Pharm. Sci. 50, 874-875.
8. Korsmeyer, R.W., Gurny, R., Doelker, E., Buri, P. and Peppas, N.A. 1983. Mechanisms of solute release from porous hydrophilic polymers. Int. J. Pharm. 15, 25-35.

9. Peppas, N.A. 1985. Analysis of Fickian and non-Fickian drug release from polymers. Pharm. Acta. Helv. 60, 110-111.

10. Chueh, H.R., Zia, H. and Rhodes, C.T. 1995. Optimization of sotalol floating and bioadhesive extended release tablet formulations. Drug Dev. Ind. Pharm. 21, 1725-1747.

11. Dow chemical information site (http://www.dow.com/ dowexcipients/products/methocel.htm).

12. BASF information site (http://www.pharma-solutions. basf.com/direct_compressible_excipients.aspx). 